\title{
Effect of Heaving Movement on Flow Instability in U-Tubes of Marine Steam Generator under Natural Circulation
}

\author{
Jianli Hao, ${ }^{1}$ Wenzhen Chen, ${ }^{1,2}$ and De Zhang ${ }^{1}$ \\ ${ }^{1}$ Department of Nuclear Energy Science and Engineering, Naval University of Engineering, Wuhan 430033, China \\ ${ }^{2}$ Institute of Thermal Science and Power Engineering, Naval University of Engineering, Wuhan 430033, China
}

Correspondence should be addressed to Wenzhen Chen; cwz2@21cn.com

Received 30 May 2013; Accepted 2 October 2013

Academic Editor: Leon Cizelj

Copyright (C) 2013 Jianli Hao et al. This is an open access article distributed under the Creative Commons Attribution License, which permits unrestricted use, distribution, and reproduction in any medium, provided the original work is properly cited.

Under heaving movement conditions, the single phase flow instability in U-tubes is affected by the additional force, which will influence the marine reactor operation. In the present work, one-dimensional thermal-hydraulic model in U-tubes under heaving movement conditions is established, and the critical pressure drop (CPD) and critical mass flow rate (CMFR) which relate to the occurrence of reverse flow in U-tubes are proposed and analyzed. The effects of the heaving period and heaving acceleration amplitude on the flow instability in U-tubes with the different length are discussed. It is shown that (1) the CPD and CMFR are obviously affected by the heaving movement, which means that the reverse flow characteristic in U-tubes will be changed; (2) the fluctuation periods of the CPD and CMFR are the same as the heaving period, but the fluctuation magnitude of them is little affected by the heaving period; (3) the relative changes of CPD and CMFR are the linear function of heaving acceleration amplitude; and (4) the U-tube length has little influence on the relative changes of CPD and CMFR compared with the heaving acceleration amplitude, which means that the heaving movement has little influence on the space distribution of reverse flow in the U-tubes of marine steam generator.

\section{Introduction}

Natural circulation operation is significant for the marine nuclear power plant in terms of passive safety, efficiency, and noise decrease. The operation performance of steam generator (SG) can deeply influence the nuclear power plant safety. Under natural circulation conditions, it is shown that the single phase flow in the parallel U-tubes of SG may be unstable, and reverse flow occurs within some U-tubes $[1,2]$. Because of the occurrence of reverse flow, the effective heat transfer area of SG primary side is reduced, and the flow resistance coefficient under the natural circulation is obviously larger than that under the forced circulation. So the actual nature circulation capability of primary loop is lower than the needed value due to the reverse flow in U-tubes, which has negative influence on the operation of the marine nuclear power plant [3].

The flow instability in U-tubes is considered to be a typical Ledinegg-type single phase flow instability [4]. Yang et al. [5] developed a lumped-distribution model to calculate the reverse flow in the inverted U-tubes. Walter and Linzer [6] discussed the influence of the operating pressure on the reverse flow in natural circulation system. They thought that the design procedure for natural circulation systems with variable operating pressure should include the analysis of flow stability. Sanders [7] and Hao et al. [8] derived the relationships between the pressure drop and velocity and mass flow rate. They found that the relationship curves had a negative slope zone, where the flow in U-tubes was unstable and an excursion would occur. The pressure drop and velocity or mass flow rate at the inflexion of the curves are named the critical pressure drop (CPD) and critical velocity $(\mathrm{CV})$ or critical mass flow rate (CMFR) by Hao et al. $[9,10]$.

Under the ocean conditions, the marine nuclear power plant has different characteristic from the land-based nuclear power plant due to the heaving and rolling movement [3], and the phenomena of reverse flow in U-tubes for marine steam generator are more complicated. Pendyala et al. [11] experimentally studied the mass flow rate and pressure drop in a vertical tube under the heaving movement; the results show that the magnitude of the mass flow rate fluctuation decreases 
with the increase in Reynolds number. While the Reynolds number is greater than 5000, the effect of heaving movement on the friction factor in the tube can be ignored. The heaving movement brings on the additional pressure drop, which has large influence on the total pressure drop in the tubes. So the heaving movement essentially affects the critical mass flow rate and critical pressure drop in U-tubes. In this paper, the relationships between the pressure drop and mass flow rate under heaving movement conditions are analyzed, and the flow instability in the U-tubes is discussed.

\section{Theoretical Model}

Under low frequency conditions, the heaving movement has little influence on the turbulent flow [11]. So the flow and heat transfer in the U-tubes can be simplified as follows: (1) it is acceptable that the one-dimensional approach is sufficient for modeling the flow in the U-tubes; (2) while the inlet mass flow rate is determined, the fluid velocity in the U-tubes is not affected by the heaving movement; (3) the water density in the U-tubes can be expressed as a linear function of temperature; (4) the water in the secondary side of the SG is in the saturated state. The schematic of U-tube under heaving movement conditions is shown in Figure 1.

The total pressure drop in U-tubes under heaving movement conditions can be written as follows:

$$
\Delta p=\Delta p_{f}+\Delta p_{g}+\Delta p_{a}
$$

where $\Delta p_{f}$ is the flow resistance pressure drop, $\Delta p_{g}$ is the gravitational pressure drop, and $\Delta p_{a}$ is the additional pressure drop caused by the heaving movement. $\Delta p_{f}, \Delta p_{g}$, and $\Delta p_{a}$ can be written as follows [12]:

$$
\begin{gathered}
\Delta p_{f}=\left(\frac{f l}{d_{0}}+\zeta\right) \frac{\dot{m}^{2}}{2 A^{2} \bar{\rho}}, \\
\Delta p_{g}=-\Delta \rho g H, \\
\Delta p_{a}=-\Delta \rho H a,
\end{gathered}
$$

where $\dot{m}$ is the mass flow rate, $f$ is the friction resistance coefficient, $f=0.3164 \mathrm{Re}^{-0.25}$, Re is the Reynolds number, $l$ is the $\mathrm{U}$-tube length, $d_{0}$ is the $\mathrm{U}$-tube inside diameter, $\zeta$ is the local resistance coefficient, $\zeta=0.262+0.326\left(d_{0} / r_{u}\right)^{3.5}, r_{u}$ is the Utube bending radius, $A$ is the U-tube flow area, $\bar{\rho}$ is the average density, $\Delta \rho$ is the density difference between the cold side and hot side of the U-tube, $g$ is the gravitational acceleration, $H$ is the U-tube height, and $a$ is the heaving acceleration.

The heaving acceleration can be written as follows [3]:

$$
a=-a_{0} \sin \left(\frac{2 \pi}{T} t\right)
$$

where $a_{0}$ is the heaving acceleration amplitude, $T$ is the heaving period, and $t$ is the flow time.

The additional pressure drop caused by the heaving movement can be written as follows:

$$
\Delta p_{a}=-\Delta \rho a_{0} H \sin \left(\frac{2 \pi}{T} t\right) .
$$

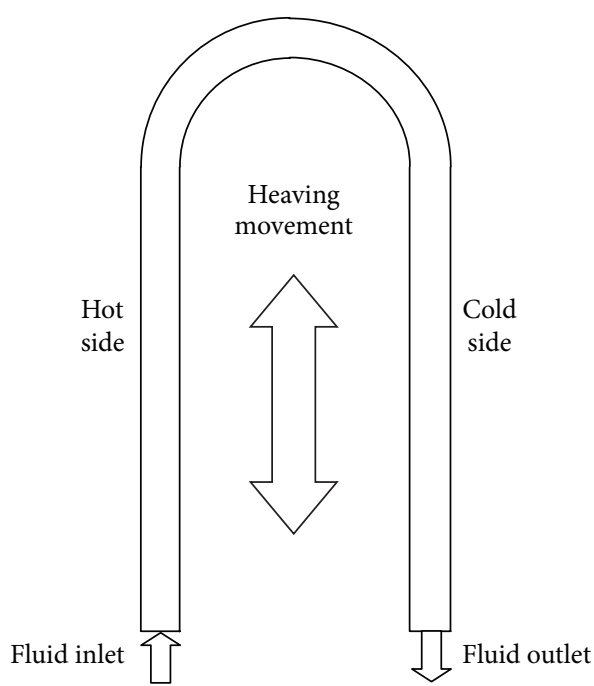

FIGURE 1: Schematic of U-tube under heaving movement conditions.

The temperature fluctuation caused by the heaving movement is little; the density change along the U-tube caused by the heaving movement conditions can be ignored [13]. Based on Boussinesq approximation, the density can be written as follows:

$$
\rho=\rho_{0}\left(1-\beta\left(T_{w}-T_{0}\right)\right)
$$

where $\rho_{0}$ is the reference density, $\beta$ is the thermal expansion coefficient, $T_{w}$ and $T_{0}$ are the flow water temperature and reference temperature, respectively.

The fluid energy conservation equation can be obtained as follows [3]:

$$
\frac{\partial T_{w}}{\partial s}=-\frac{h_{s p} P}{\dot{m} c_{p}}\left(T_{w}-T_{0}\right),
$$

where $s$ is the coordinate in the normal flow direction along the U-tube. Substituting (7) into (8) results in

$$
\frac{\partial \rho}{\partial s}=\frac{h_{s p} P}{\dot{m} c_{p}}\left(\rho_{0}-\rho\right) .
$$

While the inlet mass flow rate and fluid temperature are given, integrating (9) along the U-tube length leads to

$$
\rho=\rho_{0}-\left(\rho_{0}-\rho_{\text {in }}\right) e^{-h_{s p} P_{s} / \dot{m} c_{p}}
$$

where $\rho_{\text {in }}$ is the inlet fluid density, $c_{p}$ is the specific heat capacity, $P$ is the wetted perimeter of $\mathrm{U}$-tube, $h_{s p}$ is the overall heat transfer coefficient, $h_{s p}=1 /\left(1 / h_{0}+\left(d_{0} / 2 \lambda_{\text {wall }}\right) \ln \left(d_{1} / d_{0}\right)+\right.$ $\left.d_{0} / h_{1} d_{1}\right), h_{0}$ is the surface heat transfer coefficient of U-tube inside wall, $\lambda_{\text {wall }}$ is the U-tube thermal conductivity, $d_{1}$ is the U-tube outside diameter, and $h_{1}$ is the surface heat transfer coefficient of U-tube outside wall. 
From (10), the expressions of $\bar{\rho}$ and $\Delta \rho$ can be derived as follows:

$$
\begin{gathered}
\bar{\rho}=\rho_{0}-\left(\rho_{0}-\rho_{\text {in }}\right) \frac{\dot{m} c_{p}}{h_{s p} P l}\left(1-e^{-h_{s p} P l / m c_{p}}\right), \\
\Delta \rho=\left(\rho_{0}-\rho_{\text {in }}\right) \frac{2 \dot{m} c_{p}}{h_{s p} P l}\left(1-e^{-h_{s p} P l / 2 \dot{m} c_{p}}\right)^{2} .
\end{gathered}
$$

Inserting (11) into (2), $\Delta p_{f}$ can be obtained as follows:

$$
\begin{aligned}
\Delta p_{f}= & \left(\frac{\dot{m}^{2}\left(f l / d_{0}+\zeta\right)}{2 A^{2}}\right) \\
& \times\left(\rho_{0}-\frac{\left(\rho_{0}-\rho_{\text {in }}\right) c_{p} \dot{m}}{h_{s p} P l}\left(1-e^{-h_{s p} P l / m c_{p}}\right)\right)^{-1} .
\end{aligned}
$$

Inserting (12) into (3) and (4), respectively, $\Delta p_{g}$ and $\Delta p_{a}$ can be obtained as follows:

$$
\begin{gathered}
\Delta p_{g}=-\frac{\left(\rho_{0}-\rho_{\text {in }}\right) c_{p} \dot{m}}{h_{s p} P l / 2}\left(1-e^{-h_{s p} P l / 2 \dot{m} c_{p}}\right)^{2} H g \\
\Delta p_{a}=-2 \frac{\left(\rho_{0}-\rho_{\text {in }}\right) c_{p} \dot{m}}{h_{s p} P l}\left(1-e^{-h_{s p} P l / 2 \dot{m} c_{p}}\right)^{2} H a_{0} \sin \left(\frac{2 \pi}{T} t\right) .
\end{gathered}
$$

Substituting $\Delta p_{f}, \Delta p_{g}$, and $\Delta p_{a}$ into (1) results in

$$
\begin{aligned}
\Delta p= & \left(\frac{\dot{m}^{2}\left(f l / d_{0}+\zeta\right)}{2 A^{2}}\right) \\
& \times\left(\rho_{0}-\frac{\left(\rho_{0}-\rho_{\text {in }}\right) c_{p} \dot{m}}{h_{s p} P l}\left(1-e^{-h_{s p} P l / m c_{p}}\right)\right)^{-1} \\
& -\frac{\left(\rho_{0}-\rho_{\text {in }}\right) c_{p} \dot{m}}{h_{s p} P l / 2} \\
& \times\left(1-e^{-h_{s p} P l / 2 \dot{m} c_{p}}\right)^{2} H\left(g+a_{0} \sin \left(\frac{2 \pi}{T} t\right)\right) .
\end{aligned}
$$

While $\partial \Delta p / \partial \dot{m}<0$, the flow in U-tubes is unstable [8]. The criterion equation of flow instability in $\mathrm{U}$-tubes under the heaving movement is $\partial \Delta p / \partial \dot{m}=0$; then the following equation can be obtained:

$$
\begin{aligned}
0= & \frac{\dot{m}_{c}}{A^{2} \rho_{0}}\left(\frac{f l}{d_{0}}+\zeta\right)-\frac{\rho_{0}-\rho_{\text {in }}}{h_{s p} P} c_{p} \\
& \times\left(1-e^{-h_{s p} P l / 2 \dot{m}_{c} c_{p}}\right)^{2} H\left(g+a_{0} \sin \frac{2 \pi}{T} t\right) \\
& -2 \frac{\rho_{0}-\rho_{\text {in }}}{\dot{m}_{c}}\left(g+a_{0} \sin \frac{2 \pi}{T} t\right) \\
& \times H\left(-e^{-h_{s p} P l / 2 \dot{m}_{c} c_{p}}+e^{-h_{s p} P l / \dot{m}_{c} c_{p}}\right),
\end{aligned}
$$

where $\dot{m}_{c}$ is the critical mass flow rate (CMFR). Equation (16) is the implicit expression of $\dot{m}_{c}$, which can be solved by numerical iteration method.
TABLE 1: Parameters of marine steam generator U-tubes.

\begin{tabular}{lc}
\hline Name of parameter & $\begin{array}{c}\text { Value of } \\
\text { parameter }\end{array}$ \\
\hline Inner diameter of U-tubes, $\mathrm{m}$ & $d_{0}$ \\
Length of U-tubes, $\mathrm{m}$ & $0.7 l_{0} \sim l_{0}$ \\
Secondary side operating pressure of steam & 3.0 \\
generator, MPa & $T_{\text {in }}$ \\
Inlet fluid temperature, $\mathrm{K}$ & $d_{1}$ \\
Outside diameter of U-tubes, $\mathrm{m}$ & 14.0 \\
Primary side operating pressure of steam & \\
generator, MPa & $0.006 \sim 0.06$ \\
Mass flow rate, kg/s & 9.8 \\
Gravitational acceleration, $\mathrm{m} / \mathrm{s}^{2}$ &
\end{tabular}

Substituting CMFR obtained by (16) into (15), the critical pressure drop (CPD) can be given as follows:

$$
\begin{aligned}
\Delta p_{c}= & -\frac{\dot{m}_{c}^{2}}{2 A^{2} \rho_{0}}\left(\frac{f l}{d_{0}}+\zeta\right) \\
& -2 H\left(\rho_{0}-\rho_{\text {in }}\right) e^{-h_{s p} P l / 2 \dot{m}_{c} c_{p}}\left[g+a_{0} \sin \left(\frac{2 \pi}{T} t\right)\right] .
\end{aligned}
$$

While the mass flow rate (or total pressure drop) in Utubes is lower than $\dot{m}_{c}$ (or $\Delta p_{c}$ ), the flow in the U-tubes is unstable, and the reverse flow will occur.

\section{Numerical Experiments}

In order to validate the effect of heaving movement on the flow instability in U-tubes, a certain type of marine steam generator is selected [14], the parameters of the U-tubes are shown in Table 1 , and $l_{0}$ is the longest tube length of the marine steam generator. The inner and outside diameter and straight tube length of the U-tubes are the same, but the bending radiuses of the $\mathrm{U}$-tubes are different.

3.1. Relationships between Total Pressure Drop and Mass Flow Rate under Heaving Movement. The heaving movement period is set to be $10 \mathrm{~s}$, and the acceleration amplitude is $0.5 \mathrm{~m} / \mathrm{s}^{2}$ [3]. The variation of the heaving movement acceleration with time is shown in Figure 2. Based on (15), the variations of total pressure drop with mass flow rate for the different heaving movement time are shown in Figure 3.

From (4), it is known that the relationship between the additional pressure drop and heaving acceleration is linear. The additional pressure drop will decrease while the heaving acceleration decreases, which causes the decrease in the total pressure drop. It can be seen from Figure 3 that the heaving movement has a certain effect on the critical pressure drop (CPD) and critical mass flow rate (CMFR), which is discussed in the following section.

3.2. Effect of Heaving Period. Based on (16) and (17), the effects of heaving period on the critical pressure drop (CPD) and critical mass flow rate (CMFR) are analyzed, which are 


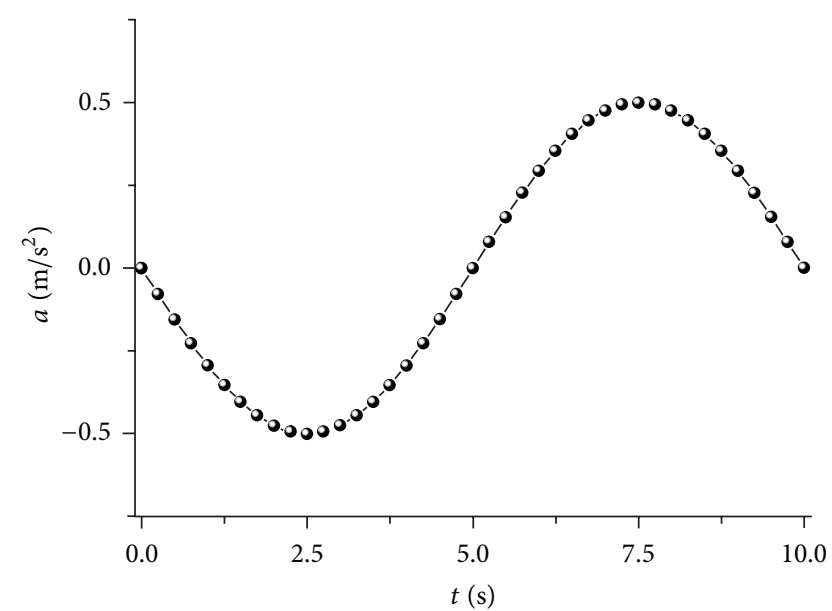

FIGURE 2: Variation of heaving movement acceleration versus time.

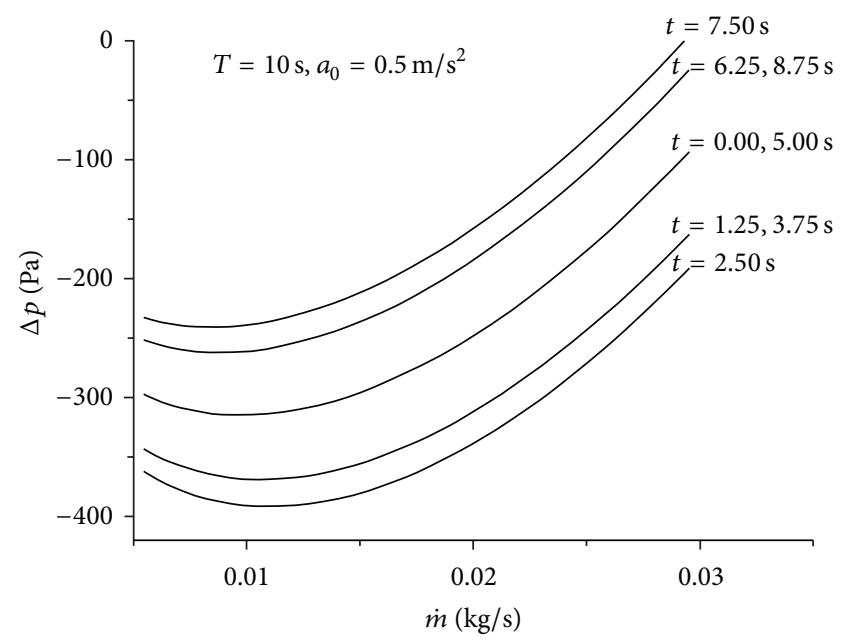

FIGURE 3: Variation of total pressure drop with mass flow rate for different time.

shown in Figures 4 and 5. Where the U-tube length is $0.7 l_{0}$, the amplitude of heaving acceleration is $0.5 \mathrm{~m} / \mathrm{s}^{2}$, and the heaving periods are $5,10,15$, and $20 \mathrm{~s}$, respectively.

From Figures 4 and 5 it can be seen that the CPD and CMFR change periodically under the heaving movement and the CMFR increases at first and last quarter time, but the variation of CPD is opposite to it. The fluctuation period is the same as the heaving period, but the heaving periods have little influence on the fluctuation magnitude of the CMFR and CPD. The data in Figures 4 and 5 are fitted; then the variation of the CMFR and CPD with time can be expressed as follows:

$$
\begin{gathered}
\dot{m}_{c}=\dot{m}_{c, 0}\left[1+0.03294 \sin \left(\frac{2 \pi}{T} t\right)\right], \\
\Delta p_{c}=\Delta p_{c, 0}\left[1+0.06 \sin \left(\frac{2 \pi}{T} t\right)\right],
\end{gathered}
$$

where $\dot{m}_{c, 0}$ and $\Delta p_{c, 0}$ are the CMFR and CPD in the steady state, respectively, $\dot{m}_{c, 0}=0.00979 \mathrm{~kg} / \mathrm{s}$, and $\Delta p_{c, 0}=$ $-314.58932 \mathrm{~Pa}$.

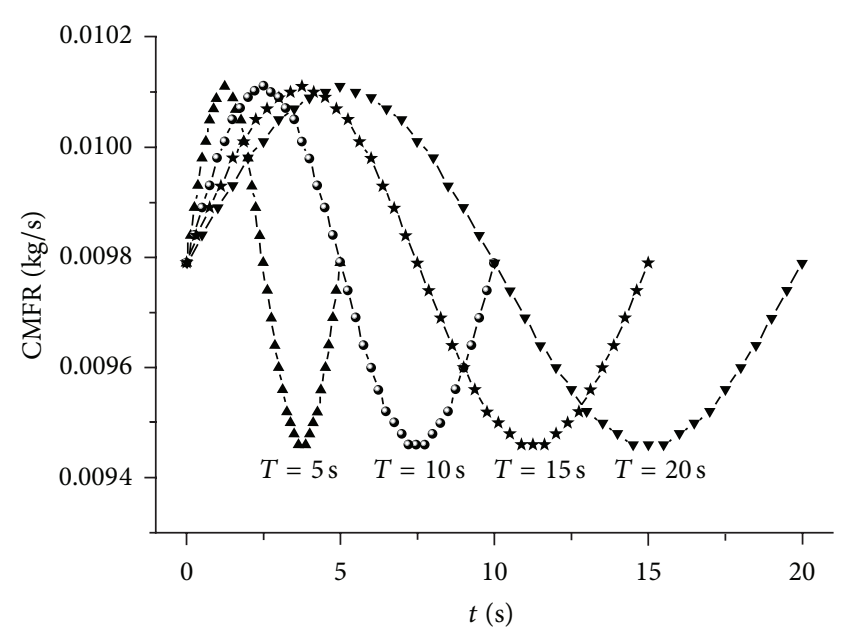

FIGURE 4: Variation of critical mass flow rate with time for different heaving period.

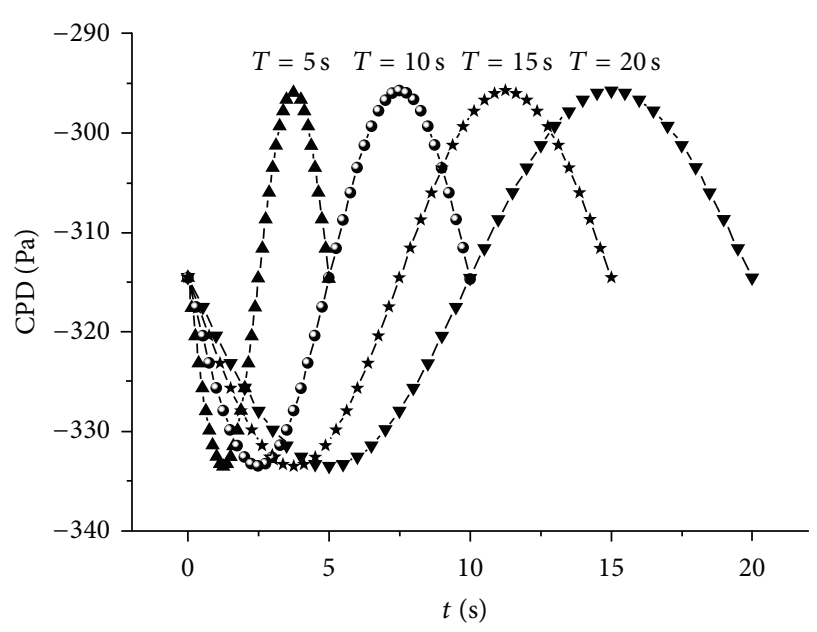

FIGURE 5: Variation of critical pressure drop with time for different heaving period.

3.3. Effect of Heaving Acceleration Amplitude. Here the Utube length is chosen as $0.7 l_{0}$, the heaving period is $10 \mathrm{~s}$, and the amplitudes of heaving acceleration are $0.5,1.0,1.5$, and $2.0 \mathrm{~m} / \mathrm{s}^{2}$, respectively. The effects of heaving acceleration amplitude on the flow instability are shown in Figures 6 and 7.

It can be seen from Figures 6 and 7 that the fluctuation magnitude of CMFR and CPD increases with the increase in the amplitude of heaving acceleration. The data in Figures 6 and 7 are fitted, and the relative change values of CMFR and $\mathrm{CPD}$ can be written as follows:

$$
\begin{aligned}
\left|\frac{\dot{m}_{c, M}-\dot{m}_{c, 0}}{\dot{m}_{c, 0}}\right| & =0.06679 a_{0}, \\
\left|\frac{\Delta p_{c, M}-\Delta p_{c, 0}}{\Delta p_{c, 0}}\right| & =0.11998 a_{0},
\end{aligned}
$$

where $\dot{m}_{c, M}$ and $\Delta p_{c, M}$ are the maximum values of CMFR and $\mathrm{CPD}$ in the heaving period, respectively. 


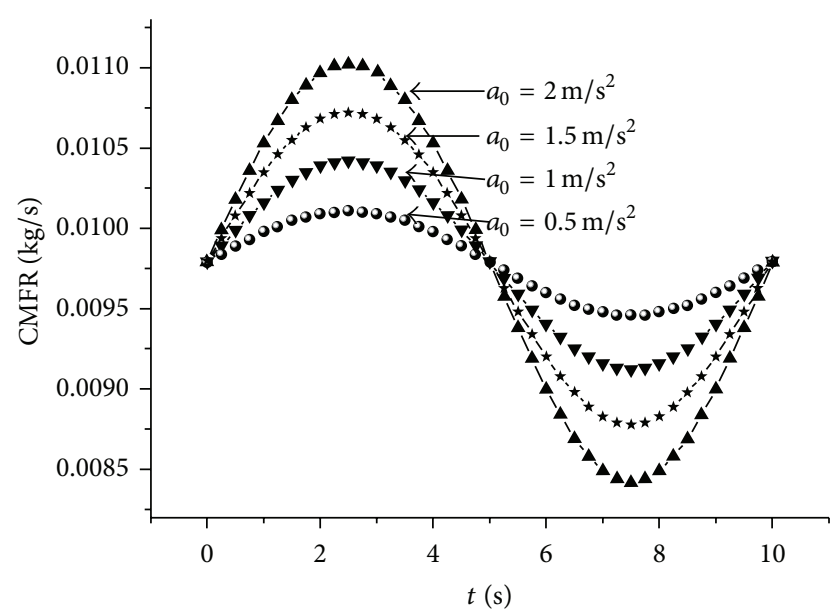

FIGURE 6: Variation of critical mass flow rate with time for different amplitude of heaving acceleration.

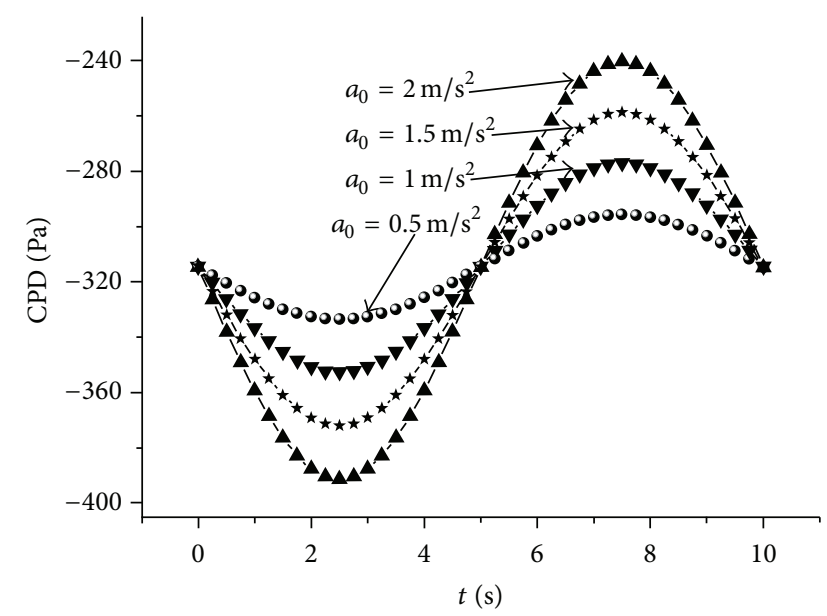

FIGURE 7: Variation of critical pressure drop with time for different amplitude of heaving acceleration.

Combining (18) and (20), the variation of CMFR with time under the heaving movement can be obtained as follows:

$$
\dot{m}_{c}=\dot{m}_{c, 0}\left[1+0.06679 a_{0} \sin \left(\frac{2 \pi}{T} t\right)\right]
$$

Combining (19) and (21), the variation of CPD with time under the heaving movement can be obtained as follows:

$$
\Delta p_{c}=\Delta p_{c, 0}\left[1+0.11998 a_{0} \sin \left(\frac{2 \pi}{T} t\right)\right] .
$$

3.4. Effect of Heaving Movement on Flow Instability in UTubes with Different Length. Based on (16) and (17), the flow instability in U-tubes with different length under the heaving movement is investigated, and the results are shown in Figures 8-11.

In Figures 8 and 9, the heaving period is $10 \mathrm{~s}$ and the amplitude of heaving acceleration is $0.5 \mathrm{~m} / \mathrm{s}^{2} \cdot l=0.7 l_{0}$ and $l=$ $l_{0}$ are the shortest and longest length of $\mathrm{U}$-tubes in the marine

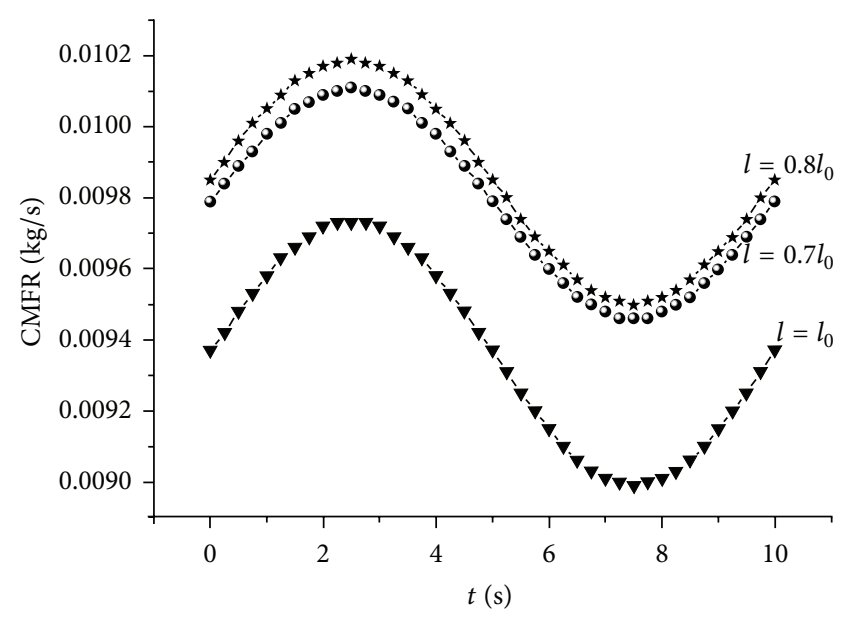

FIGURE 8: Variation of critical mass flow rate with time for different length.

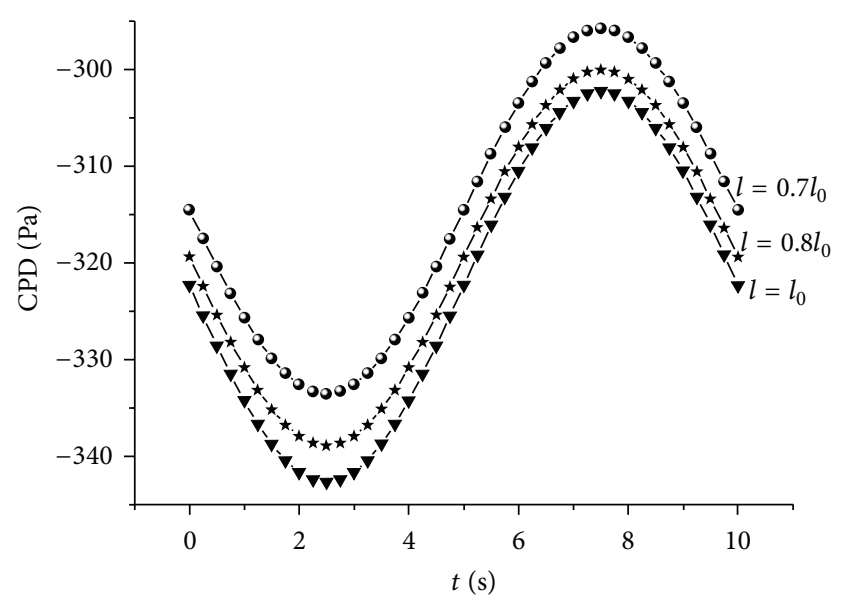

FIGURE 9: Variation of critical pressure drop with time for different length.

steam generator, respectively. It can be seen from Figure 8 that the CMFR of both the long tube $\left(l=l_{0}\right)$ and short tube $(l=$ $0.7 l_{0}$ ) is lower than that of the U-tube with the middle length $\left(l=0.8 l_{0}\right)$.

It can be seen from Figure 9 that the CPD of short tube $\left(l=0.7 l_{0}\right)$ is higher than that of others, which means that the reverse flow will occur in the short tube easily. From Figures 8 and 9, it can be also found that the effects of heaving movement on the flow instability in U-tubes with different length are similar, which means that the heaving movement has little influence on the space distribution of reverse flow.

Figures 10 and 11 give the relative changes of the CMFR and CPD with U-tube length. Where the heaving period is $10 \mathrm{~s}$ and the amplitudes of heaving acceleration are $0.5,1.0$, 1.5 , and $2.0 \mathrm{~m} / \mathrm{s}^{2}$, respectively. It can be seen from Figures 10 and 11 that the amplitude of heaving acceleration has large influence on the relative changes of CMFR and CPD; namely, the CMFR and CPD increase with the increase in the heaving acceleration amplitude. However the effect of U-tube length on the CMFR is more obvious than that on the CPD. 


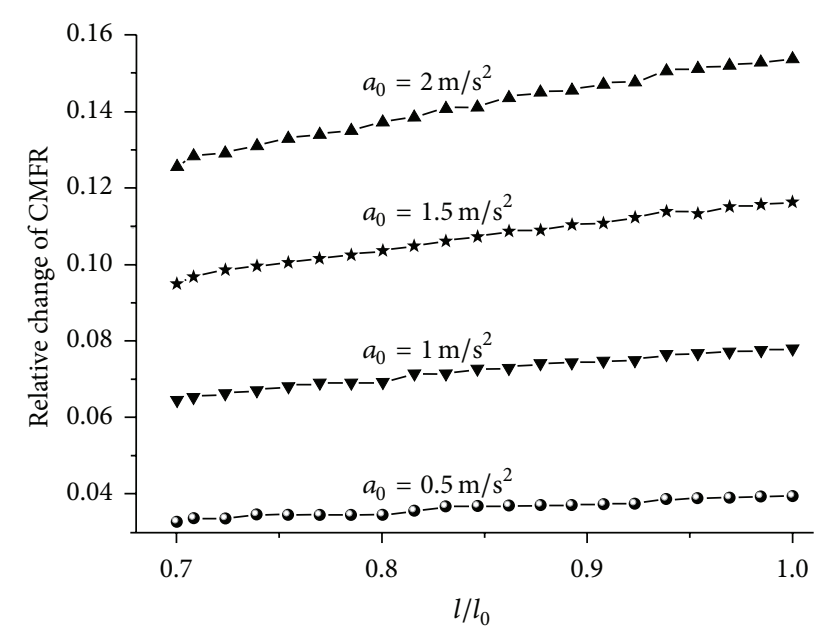

FIGURE 10: Relative change of critical mass flow rate with U-tube length.

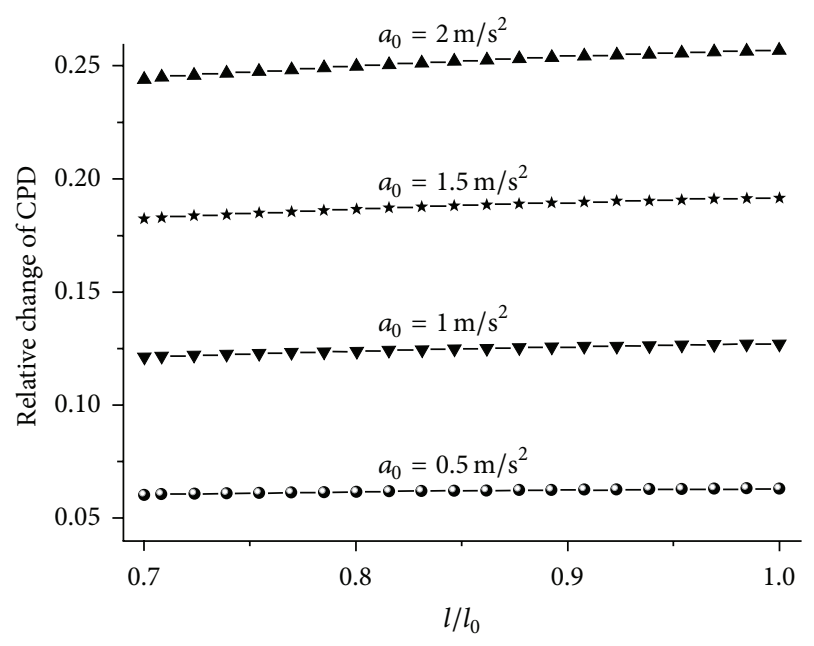

FIGURE 11: Relative change of critical pressure drop with U-tube length.

\section{Conclusions}

Under heaving movement conditions, the critical pressure drop (CPD) and critical mass flow rate (CMFR) are given and analyzed, which relate to the occurrence of reverse flow in U-tubes. One-dimensional thermal-hydraulic model is established, and the effects of heaving movement on the flow instability in U-tubes are discussed. The detailed conclusions are drawn as follows.

(1) While the heaving acceleration decreases, the additional and total pressure drop will decrease, and the variation of total pressure drop and mass flow rate with time agrees with that of heaving acceleration. The heaving movement will affect the occurrence of reverse flow in the marine steam generator U-tubes.

(2) The fluctuation periods of CPD and CMFR are the same as the heaving period, but the heaving period has little influence on the CPD and CMFR fluctuation magnitude.

(3) The variations of CPD and CMFR with time under the heaving movement are derived, which are the linear function of the heaving acceleration amplitude.

(4) The U-tube length has little influence on the relative change of CPD and CMFR compared with the heaving acceleration amplitude, which means that the heaving movement has little influence on the space distribution of reverse flow in marine steam generator U-tubes.

\section{Acknowledgments}

This research is supported by the Doctorial Innovation Fund of Naval University of Engineering and the Natural Science Foundation of Naval University of Engineering.

\section{References}

[1] Y. Kukita, H. Nakamura, K. Tasaka, and C. Chauliac, "Nonuniform steam generator U-Tube flow distribution during natural circulation tests in ROSA-IV large scale test facility," Nuclear Science and Engineering, vol. 99, no. 4, pp. 289-298, 1988.

[2] F. Wang, W.-B. Zhuo, Z.-J. Xiao, and B.-D. Chen, "Phenomena and analysis of reversal flow in vertically inverted U-tube steam generator," Atomic Energy Science and Technology, vol. 41, no. 1, pp. 65-68, 2007 (Chinese).

[3] W. Z. Chen, L. Yu, and J. L. Hao, Thermal Hydraulics of Nuclear Power Plants, Chinese Atomic Energy Press, Bejing, China, 2013, (Chinese).

[4] I. Babelli and M. Ishii, "Flow excursion instability in downward flow systems: part I. Single-phase instability," Nuclear Engineering and Design, vol. 206, no. 1, pp. 91-96, 2001.

[5] R.-C. Yang, J.-G. Liu, Y.-P. Huang, R.-L. Liu, and S.-W. Qin, "Calculation of reverse flow in inverted U-tubes of steam generator during natural circulation," Hedongli Gongcheng/Nuclear Power Engineering, vol. 31, no. 1, pp. 57-60, 2010 (Chinese).

[6] H. Walter and W. Linzer, "The influence of the operating pressure on the stability of natural circulation systems," Applied Thermal Engineering, vol. 26, no. 8-9, pp. 892-897, 2006.

[7] J. Sanders, "Stability of single-phase natural circulation with inverted U-tube steam generators," Journal of Heat Transfer, vol. 110, no. 3, pp. 735-742, 1988.

[8] J. L. Hao, W. Z. Chen, D. Zhang, and S. M. Wang, "Scaling modeling analysis of flow instability in U-tubes of steam generator under natural circulation," Annals of Nuclear Energy, vol. 64, pp. 169-175, 2014.

[9] J. L. Hao, W. Z. Chen, and D. Zhang, "Effect of U-tube length on reverse flow in UTSG primary side under natural circulation," Annals of Nuclear Energy, vol. 56, pp. 66-70, 2013.

[10] J. L. Hao, W. Z. Chen, and S. M. Wang, "Flow instability analysis of U-tubes in SG based on CFD method," Progress in Nuclear Energy, vol. 70, pp. 134-139, 2014.

[11] R. Pendyala, S. Jayanti, and A. R. Balakrishnan, "Flow and pressure drop fluctuations in a vertical tube subject to low frequency oscillations," Nuclear Engineering and Design, vol. 238, no. 1, pp. 178-187, 2008. 
[12] Z. Y. Chen, J. L. Hao, and W. Z. Chen, "The development of fast simulation program for marine reactor parameters," Annals of Nuclear Energy, vol. 40, no. 1, pp. 45-52, 2012.

[13] S.-Y. Jiang, X.-T. Yang, H.-J. Gong et al., "Mechanism of natural circulation taking account into heaving movement," Atomic Energy Science and Technology, vol. 43, no. 1, pp. 92-96, 2009 (Chinese).

[14] J. L. Hao, W. Z. Chen, and S. M. Wang, "Investigation on factors affecting reverse flow in inverted U-tubes of steam generator under natural circulation," Atomic Energy Science and Technology, vol. 47, no. 1, pp. 65-69, 2013 (Chinese). 


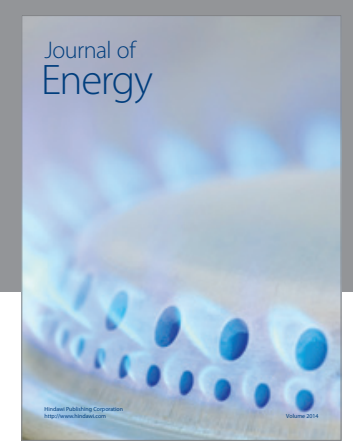

Journal of

Industrial Engineering
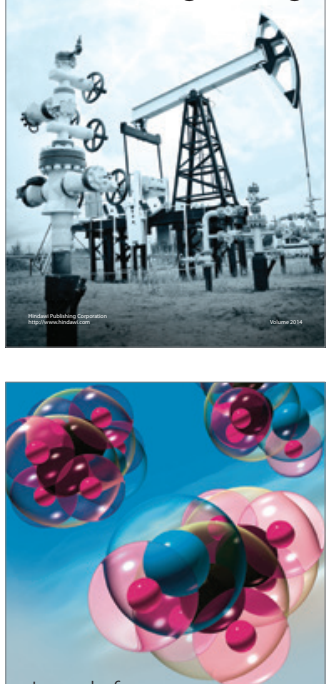

Fuels
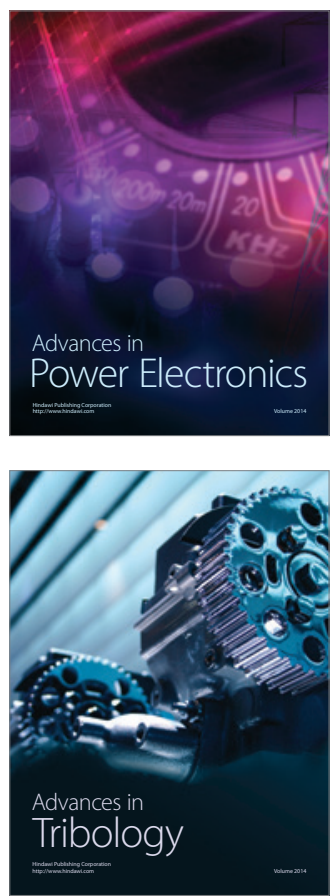

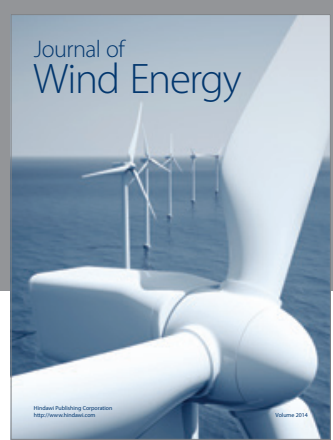

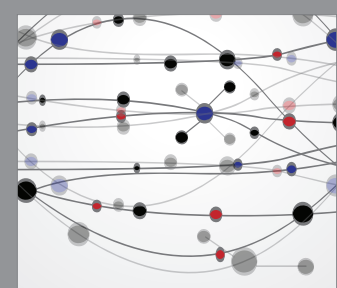

The Scientific World Journal

Submit your manuscripts at http://www.hindawi.com

Journal of

Structures
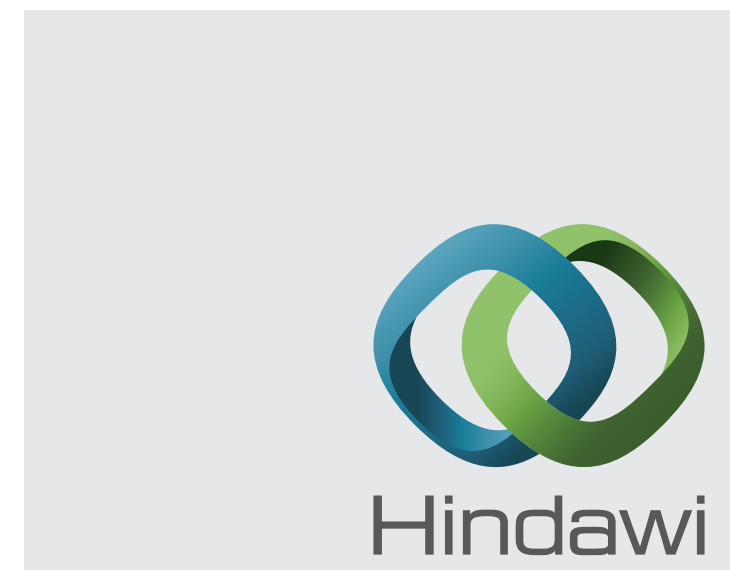

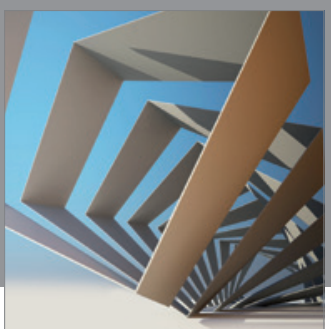

Rotating

Machinery
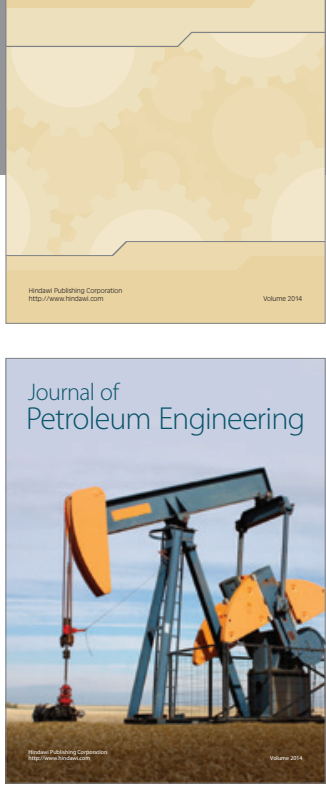

Journal of

Solar Energy
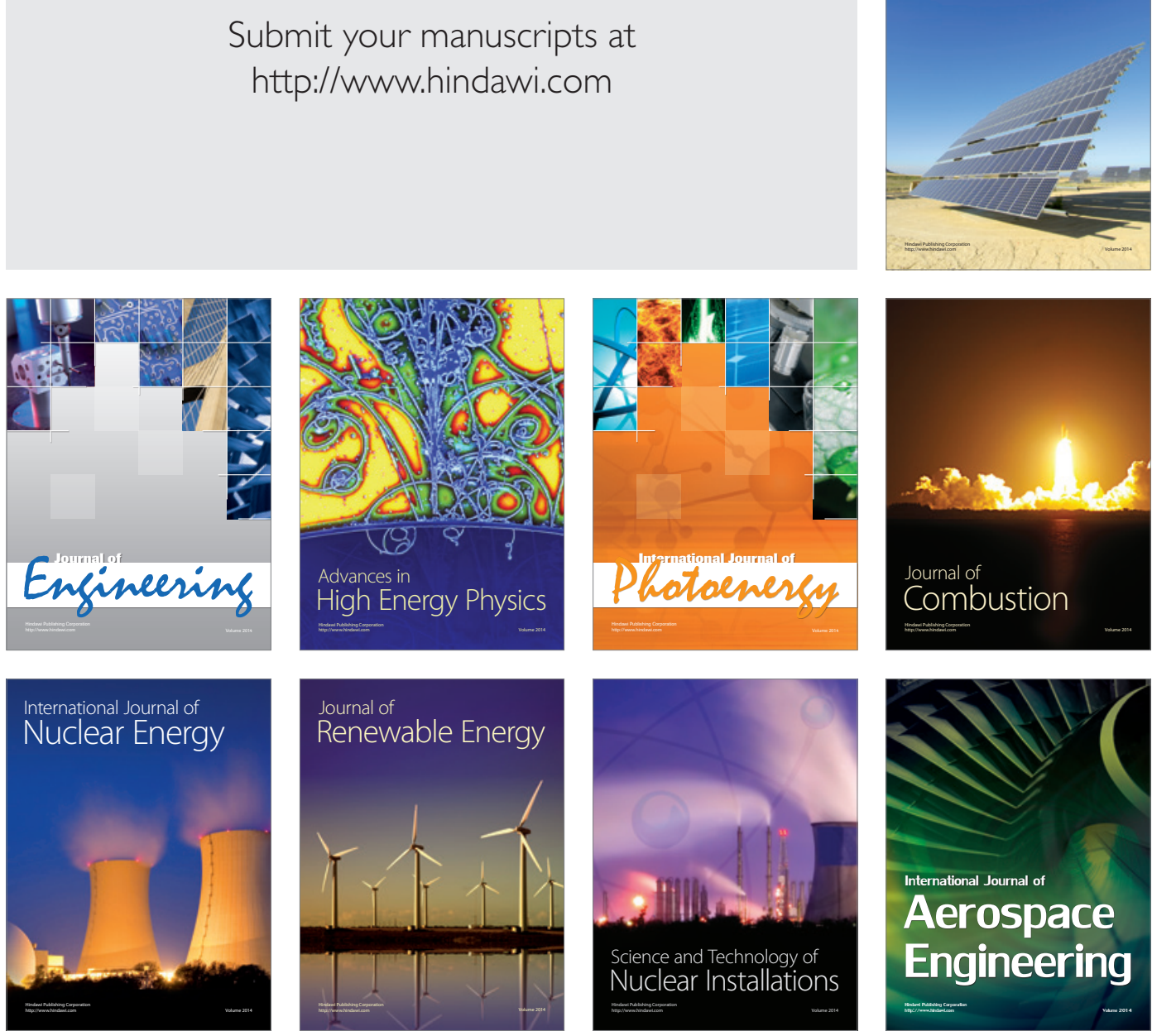